\title{
A Note on Controlled Composition in Japanese EFL Classes for Intermediate Learners: With a Focus on Reordering Questions
}

\author{
Shimpei HASHIO ${ }^{1}$ and Nobuyuki YAMAUCHI ${ }^{2}$ \\ ${ }^{1}$ Doshisha University, Kyoto 610-0394, Japan \\ smp.hashio@gmail.com \\ ${ }^{2}$ Doshisha University, Kyoto 610-0394, Japan \\ nyamauch@mail.doshisha.ac.jp
}

\begin{abstract}
Controlled composition can be an important and useful method for Japanese EFL learners preparing to study Japanese-to-English translation and paragraph writing. This paper focuses on reordering questions, one traditional type of controlled composition. It compares intermediate-level learners' English sentences in reordering questions with their counterparts in translation questions in the same Japanese sentences, and considers what reordering questions should be like and what intermediate-level learners should study in their composition classes. The results show that students are likely to make significantly more errors related to verbs, prepositions, articles, and pronouns in the translation questions than in the reordering questions. In conclusion, English classes for intermediate-level learners in Japan should make better use of reordering exercises as well as Japanese-to-English translation and paragraph writing by giving more explicit instruction designed to make learners more conscious of the uses of the word classes whose errors are likely to occur more frequently when learners both translate and deal with reordering questions.
\end{abstract}

Keywords: Japanese EFL learners, composition instruction, reordering

\section{Introduction}

Writing instruction in Japan has long depended on a method called controlled composition including such tasks as fill-in-the-blank, conversion, and reordering, some of which have been adopted in formal school education. Controlled composition are considered to work as a bridge between the basic-level instruction of grammar and vocabulary and advanced-level instruction of Japanese-to-English translation and paragraph writing. Kimura et al. [4] argued that the instruction in controlled composition facilitates acquisition of correct grammatical structures and reduces teachers' workload, but it also pointed out that it may degenerate into mere grammar learning or have the effect of demotivating learners so that such questions are prepared according to the intentions of teachers or teaching material designers.

This paper will examine how using reordering questions, the type of controlled composition most commonly adopted in writing instruction, can contribute to the development of learners' sentence production. 


\section{Previous Research}

"Reordering questions" is an activity that requires examinees to reorder shuffled word chunks to make a coherent sentence frequently used in university entrance examinations and writing instruction in Japan. Fig. 1 is an actual question given at the National Center Test for University Admissions in 2006.

Q1 Taking a warm better.

(1) may (2) you (3) help (4) sleep (5) bath

Fig.1. A sample of reordering questions

Morishita \& Yamamoto [6] reported that a four-month session of reordering training for elementary-level Japanese EFL learners improved their sentence production ability. The report pointed out that after the training, the learners' scores of reordering questions improved with their increased consciousness of sentence structures. Sase [7] argued that learners with a high rate of correct answers in reordering questions were likely to produce more English sentences in correct word order in speaking, and that a test of storytelling and reordering questions suggested a correlation between them. Furthermore, it pointed out a problem in learners' sentence production in which their answers in the storytelling test had a tendency to avoid and paraphrase complex structures, a learner behavior called "avoidance" (e.g. [1]).

In addition, in order to reveal the contribution of reordering questions to the learners' sentence production, we must confirm the characteristic of learners' English sentences they made from scratch without any hints. Tono \& Mochizuki [8] analyzed the JEFLL Corpus, a learner corpus collecting essays written in English by students from Years 7 to 12, and classified the detected errors into the three types of errors proposed by James [3]: misformation (use of incorrect word class or form), omission (lack of necessary words), and addition (use of unnecessary words). The analysis showed a high frequency of errors in nouns, adverbs and prepositions, and many omission errors in articles and prepositions.

\section{Research}

\subsection{Research Purpose}

Based on these previous studies, this paper aims to carefully examine the characteristics of the English sentences used as answers to reordering questions and translation questions made from the same Japanese sentences. It thus identifies the points of attention in the transitional stage between the instruction of controlled composition and that of Japanese-to-English translation and paragraph writing, and examines how reordering should be adopted as part of instruction at the intermediate level between the basic and advanced levels. This study conducts questionnaires of reordering questions and translation questions among Japanese learners of English. It then analyzes the English sentences in the answers. 


\subsection{Participants}

The Japanese EFL learners participating in this study consisted of 20 students from private co-educational high school A in Osaka Prefecture and 20 students from private girls' high school B in Kyoto Prefecture. Many of the students in these two schools had obtained either EIKEN Grade Pre-2 or Grade 2 or the TOEIC scores within the test range between 300 and 500, which indicates that the students of these schools had intermediate-level English proficiency on average.

\subsection{Preparing and Conducting the Questionnaires}

Twenty reordering questions were selected from Ishiguro et al. [2], Kobayashi \& Hayasaki [5], and Yamauchi et al. [9], which are writing textbooks including reordering questions, and were labeled Q1 to Q20. The degree of difficulty in the twenty questions was adjusted based on the results of the preliminary research. They were then organized into Questionnaire X and Questionnaire Y as shown in Table 1 below for the comparison of answers to different types of questions made from the same set of Japanese sentences. Questionnaire X was answered by participants from high school A. In this questionnaire, Q1 to Q10 were given as reordering questions as in the original text, while Q11 to Q20 were given as translation questions, deleting the chunks of reordering questions and leaving only the Japanese sentences. Meanwhile, participants from high school B answered Questionnaire Y, with Q 1 to Q10 as translation questions and Q 11 to Q20 as reordering questions. Preparing questionnaires in this way enabled the analysis of the answers to apply to both reordering questions and translation questions made from the same set of Japanese sentences. Fig. 3 shows a part of the Questionnaire X and Fig. 4 represents a part of each questionnaire.

Table 1. The detail of Questionnaire X and Y

\begin{tabular}{|c|c|c|c|}
\hline & Group & Reordering & Translation \\
\hline Questionnaire X & High school A & Q1-10 & Q11-20 \\
\hline Questionnaire Y & High school B & Q11-20 & Q1-10 \\
\hline
\end{tabular}

1. 次の $(1) \sim(10)$ の日本語文に合うように[ ]内の語句を並び替えよ。

(1) その歌手はたくさんの子どもたちに取り囲まれた。 [a / surrounded / of / by / kids / lot / singer / was / the].

(2) 部屋に入ると、見知らぬ人が僕を待っていた。[the / waiting / found / a / me / entering / room / stranger / for / I].

$\vdots$

2. 次の $(1) \sim(10)$ の日本語を英語に訳せ。

(1) こう私に言つた男は、名前を名乗ることを拒否した。

(2) 彼は少年の頃から両親に虐待されてきた。

$\vdots$

Fig. 3. A part of the Questionnaire X for high school A 


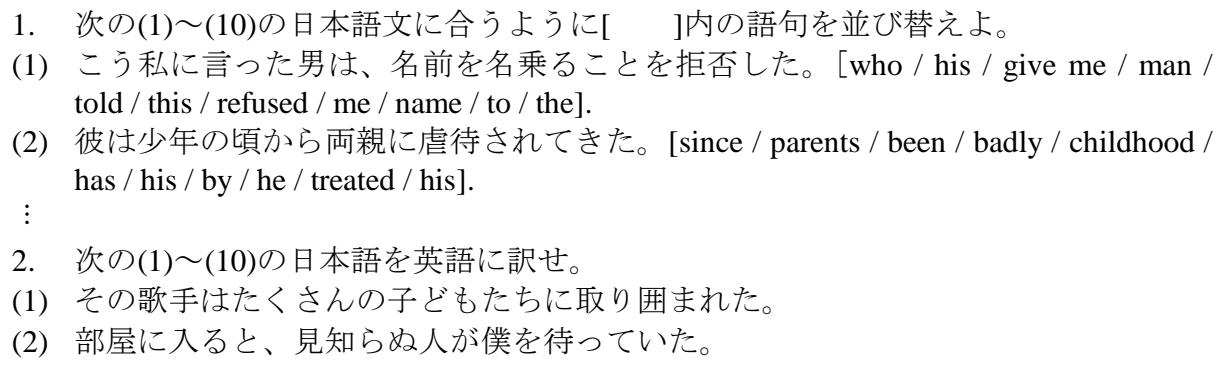

Fig. 4. A part of the Questionnaire Y for high school B

\subsection{Statistical Analysis}

In order to examine the differences in characteristics between the English sentences for the reordering exercises and those of the translation exercises, an analysis of how the three types of errors suggested by James [3] occur in reordering and translation was conducted for each word class. After collecting the sentences given by all participants separately for reordering and translation, word class tags are applied using CLAWS C7 tagset and the numbers of conjunctive (COJ), adjective (ADJ), adverb (ADV), preposition (PRP), article (AT), pronoun (PRN), noun (NOUN) and verb (VERB) are counted on AntConc. Then, the frequencies of the correct uses and errors of eight word classes are organized separately for reordering and translation. Errors are categorized into misformation, omission and addition. Each word class was labeled as "RO_ADJ" for adjectives in reordering and "TR_VERB" for verbs in translation, and the frequencies of the correct uses and three types of errors were calculated. A calculation on a $16 \times 4$ cross table and a 4-axe correspondence analysis revealed how word classes in reordering and translation relate to three error types, respectively.

\section{$4 \quad$ Results}

Table 2 shows the percentage of correct uses and three types of errors of the eight word classes for reordering and translation, respectively. With most word classes, the percentage of correct uses decreased when the question type changed from reordering to translation. Though this result looks natural based on the results of the correspondence analysis, we further examined what types of error in which word classes became prominent when the question type changed from reordering to translation.

Fig. 3 shows the results of the correspondence analysis of the relation between word classes and correct uses and errors in reordering questions and translation questions. The contribution ratio is $50.2 \%$ for the first component and $39.4 \%$ for the second component, and Fig. 3 is considered to have the interpretability of approximately $90 \%$.

Table 2. The percentage of correct uses and errors of 8 word classes in questions 


\begin{tabular}{|c|c|c|c|c|c|}
\hline Word class & Questions & Misformation & Omission & Addition & Correct use \\
\hline Verb & Translation & $23.5 \%$ & $3.9 \%$ & $0.2 \%$ & $72.4 \%$ \\
\hline Verb & Reordering & $3.5 \%$ & $2.2 \%$ & $3.0 \%$ & $91.2 \%$ \\
\hline Article & Translation & $4.4 \%$ & $18.2 \%$ & $1.8 \%$ & $75.6 \%$ \\
\hline Article & Reordering & $1.0 \%$ & $5.1 \%$ & $6.1 \%$ & $87.8 \%$ \\
\hline Pronoun & Translation & $3.0 \%$ & $12.8 \%$ & $0.9 \%$ & $83.3 \%$ \\
\hline Pronoun & Reordering & $0.2 \%$ & $2.3 \%$ & $4.4 \%$ & $93.1 \%$ \\
\hline Proposition & Translation & $21.1 \%$ & $16.7 \%$ & $7.2 \%$ & $55.0 \%$ \\
\hline Proposition & Reordering & $1.8 \%$ & $0.6 \%$ & $2.4 \%$ & $95.2 \%$ \\
\hline Noun & Translation & $7.1 \%$ & $2.6 \%$ & $0.9 \%$ & $89.4 \%$ \\
\hline Noun & Reordering & $1.1 \%$ & $1.8 \%$ & $1.4 \%$ & $95.8 \%$ \\
\hline Adverb & Translation & $2.6 \%$ & $15.9 \%$ & $2.6 \%$ & $78.8 \%$ \\
\hline Adverb & Reordering & $0.5 \%$ & $18.8 \%$ & $16.5 \%$ & $64.2 \%$ \\
\hline Adjective & Translation & $8.4 \%$ & $2.7 \%$ & $0.8 \%$ & $88.2 \%$ \\
\hline Adjective & Reordering & $0.0 \%$ & $3.0 \%$ & $3.0 \%$ & $94.0 \%$ \\
\hline Conjunctive & Translation & $5.1 \%$ & $3.8 \%$ & $0.0 \%$ & $91.1 \%$ \\
\hline Conjunctive & Reordering & $0.0 \%$ & $0.0 \%$ & $0.0 \%$ & $100.0 \%$ \\
\hline
\end{tabular}

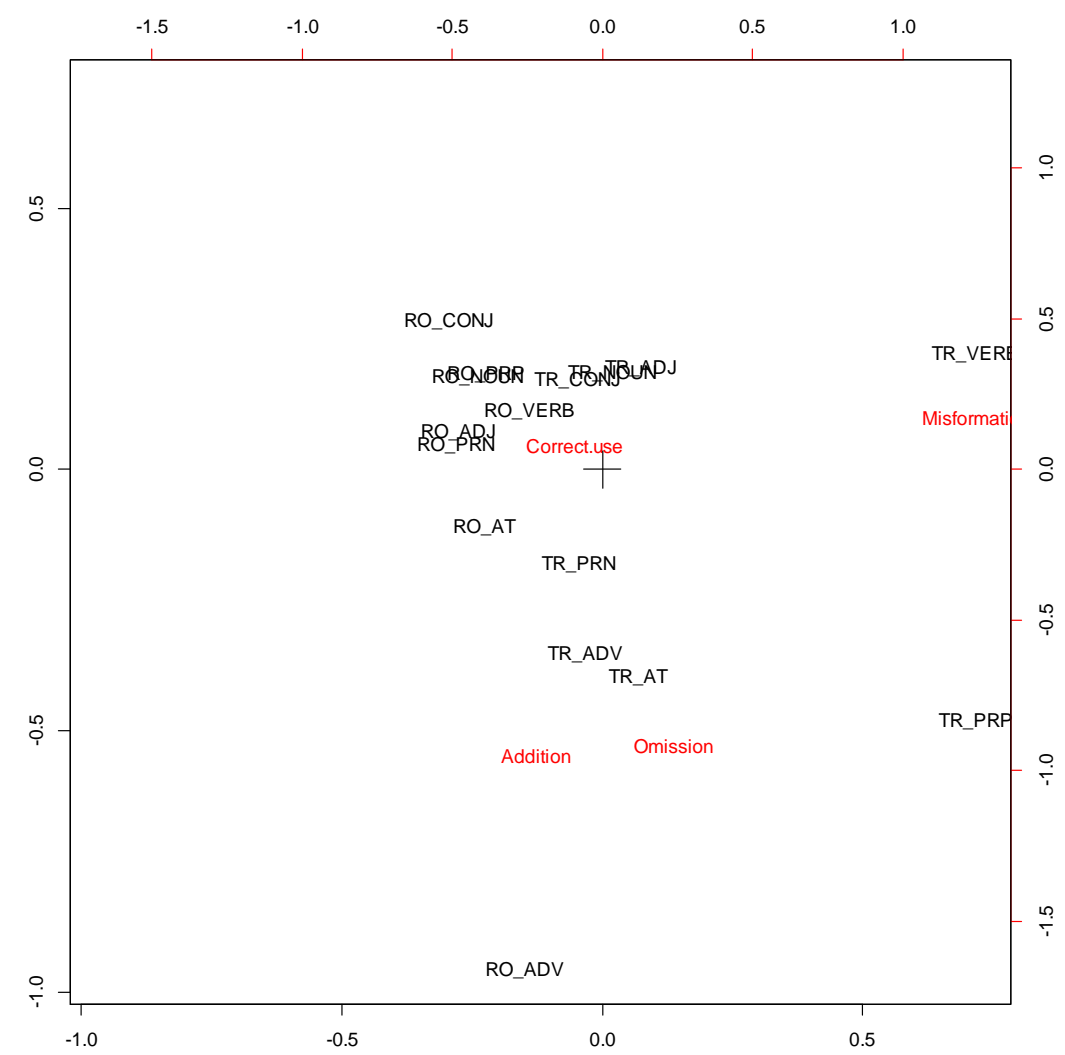

Fig. 3. The result of correspondence analysis between word classes and questions 
As seen in Fig. 3, misformation errors increase in verbs and prepositions in particular when the question type changed from reordering to translation, while omission errors increase in pronouns, prepositions and articles. Regarding verbs, singular/plural and tense errors were observed in the intermediate-level learners, as well. As for pronouns, omissions of second person subject and possessive form occur frequently, and the results also indicate that many students do not seem to understand the appropriate use of prepositions. Note that this paper will not discuss adverb errors as these omission errors occur equally frequently in both translation and reordering questions.

\section{Discussion}

In this chapter, based on the previous studies and the present results, we will examine the merits and demerits of the traditional instruction of reordering and discuss how we should make better use of reordering in writing instruction.

As Morishita \& Yamamoto [6] argued, practicing reordering improves elementary-level learners' consciousness of word order and sentence structure, and as Sase [7] argued, it also leads to the development of Japanese paraphrasing ability so as to choose the most appropriate sentence patterns that learners feel confident in using. But, as indicated by the results in this paper, reordering exercises do not seem to be sufficient for learners to acquire the correct use of verbs, pronouns, prepositions and articles. The chunks in reordering can act as too broad hints and keep learners from finding the errors in these word classes in translation and paragraph writing. For intermediate level, a transition from the instruction of reordering to that of translation and paragraph writing would be ideal. Then, it is necessary to give them explicit instructions with an emphasis on the use of such frequently misused word classes.

Yet, the answers of translation and paragraph writing are not always fixed unlike reordering questions, and scoring learners' answer or giving feedback can be a burden on teachers. Also, as Sase [7] pointed out, since some grammatical items and expressions tend to be avoided by learners, it is also necessary to adopt motivated instruction to prevent the avoidance of complex sentence structures. In the instruction of translation and paragraph writing, however, if we attempt to give explicit instructions with an emphasis on the use of such frequently misused word classes based on the result in this paper, we can easily overcome these dilemmas.

Some strategies of instruction of translation and paragraph writing have been suggested by Kimura et al. [4] and others. One effective method is to intentionally choose the type and method of feedback according to the level of learners and specify a time for feedback in every class, so as to draw the attention of learners to potential errors in specific items. When we give the instructions of paragraph writing, aiming at the misuses of verbs, giving feedback to students by focusing on verb tenses and conjugation is as effective in terms of both explicit instruction to learners and reduction of the burden on teachers as we give reordering questions.

In addition, we introduce an example to stop learners' avoidance of complex items and expressions. If we want learners to produce relative pronouns that most learners find difficult to use, another possible way is, for example, to instruct learners to use, 
for example, at least 15 words per sentence, which will create a situation where they need to use relative pronouns. Furthermore, a direct instruction like "use a relative pronoun in each sentence" is also instructive in acquiring the ability to use relative pronouns in sentence production. These are a few ways to maintain the advantages of controlled composition in instructing translation and paragraph writing.

Meanwhile, we suggest another way to utilize reordering questions for the acquisition of new grammatical items and vocabulary. The downside of reordering exercises mentioned in this paper is that word chunks give too many hints to the correct answer. In this regard, this paper turns out to be more persuasive in suggesting that the use of reordering questions focusing on frequently misused word classes with the chunks in reordering questions including an unnecessary or missing component in order to make learners more conscious of the usage of particular word classes.

\section{Summary and Further Implications}

In this paper, we have analyzed the characteristics of the English sentences in both reordering and translation exercises and also clarified how learners' error patterns in reordering are different from those in translation. We conclude that there may be good uses for reordering questions in the beginning level required to acquire a basic knowledge of word order, but its effectiveness for intermediate students is limited, and reordering exercises do not follow that they can be expected to correctly use verbs, pronouns, prepositions and articles. With the limitation of the exercise of only reordering for intermediate-level learners, it is essential to increase opportunities for them to tackle Japanese-English translation and paragraph writing and be made explicitly conscious of the word classes whose errors are frequently observed.

On the other hand, instruction in controlled composition has the advantages of clarifying the important points and, most of all, reducing the workload of teachers. In instruction focusing on outputs, it is important to take into consideration the need to efficiently teach learners. It seems beneficial to both learners and teachers to give learners such kinds of writing instruction as Kimura et al. [4] suggested.

It is unrealistic to drastically decrease the practices in formal school education, because it is part of traditional writing instruction. However, teachers should reconsider how to use reordering in view of the fact that the course guidelines in Japan are trying to increase opportunities for learners to express themselves in English.

*We appreciate Prof. Neil Heffernan of Kurume University for proofreading the first version and Prof. Susan Pavloska of Doshisha University for checking the final version. Special thanks are due to the three anonymous reviewers and the editors of the EUROPHRAS 2017 Programme Committee for their comments and encouragement. All remaining errors and inadequacies are, of course, our own. A part of this paper is supported by the research grant from the Graduate School of Culture and Information Science, Doshisha University. 


\section{References}

1. Ellis, R.: Understanding Second Language Acquisition. Oxford University Press, Oxford (1985).

2. Ishiguro, T., Yamauchi, N., Kitabayshi, T., Akaso, N.: ENGLISH COMPOSITION AT WORK: Hyougen no tameno Hasshingata Eisakubun [Productive English Composition for Expression]. Kinseido, Tokyo (1994).

3. James, C.: Errors in Language Learning and Use: Exploring Error Analysis. Longman, Harlow (1998).

4. Kimura, H., Kimura, T., Shiki, O.: Riidingu to Raitingu no Riron to Jissen [Theory and Principle in Reading and Writing: Nurturing Independent Learning]. Taishukan, Tokyo (2010).

5. Kobayashi, I., Hayasaki, Y.: Maakushiki Kiso Mondaishu (5) Eigo [Goku Seijo] Goteiban [Mark-sensing Fundamental Workbook: English Reordering Questions, 5th Edition]. Kawai-publishing, Tokyo (2005).

6. Morishita, M., Yamamoto. T.: How Syntactic Processing Training Affects Oral Production of Elementary Level of Japanese ESL Learners. Linguistic Research, 30(3), 435-452 (2013).

7. Sase, F.: Supiikingu Nouryoku to Gojun Chishiki no Kanrensei ni okeru Chosa [Survey on the Relationship between Speaking Abilities and Knowledge about Word Order]. EIKEN BULLETIN, 26, 31-49 (2014).

8. Tono, Y., Mochizuki, H.: Toward Automatic Error Identification in Learner Corpora: A DP Matching Approach. Paper presented at CL2009, UK, Liverpool (2009).

9. Yamauchi, N., Akaso, N., Kitabayashi, T.: Bunpou kara Semeru Eisakubun no tameno 15 Shou [15 Chapters for English Composition Focusing on Grammar]. Eihosha, Tokyo (2005). 